\title{
Transmitted human immunodeficiency virus-1 drug resistance in a cohort of men who have sex with men in Belo Horizonte, Brazil - 1996-2012
}

\author{
Unaí Tupinambás ${ }^{1 /+}$, Helena Duani ${ }^{1}$, Ana Virgínia Cunha Martins ${ }^{1}$, \\ Agdemir Waleria Aleixo², Dirceu Bartolomeu Greco'

\begin{abstract}
Departamento de Clínica Médica, Faculdade de Medicina ²aboratório de Imunologia e Biologia Molecular, Serviço de Doenças Infecciosas e Parasitárias, Hospital das Clínicas, Universidade Federal de Minas Gerais, Belo Horizonte, MG, Brasil
\end{abstract}

\begin{abstract}
The presence of transmitted human immunodeficiency virus (HIV)-1 drug-resistance (TDR) at the time of antiretroviral therapy initiation is associated with failure to achieve viral load (VL) suppression. Here, we report TDR surveillance in a specific population of men who have sex with men (MSM) in Belo Horizonte, Brazil. In this study, the rate of TDR was evaluated in $64 \mathrm{HIV-infected} \mathrm{individuals} \mathrm{from} \mathrm{a} \mathrm{cohort} \mathrm{of} \mathrm{MSM} \mathrm{between} \mathrm{1996-June} \mathrm{2012.} \mathrm{Fifty-}$ four percent had a documented recent HIV infection, with a seroconversion time of less than 12 months. The median $\mathrm{CD}^{+}$T lymphocyte count and VL were 531 cells $/ \mathrm{mm}^{3}$ and 17,746 copies $/ \mathrm{mL}$, respectively. Considering the surveillance drug resistance mutation criteria, nine (14.1\%) patients presented TDR, of which three (4.7\%), five (7.8\%) and four $(6.2 \%)$ had protease inhibitors, resistant against nucleos(t)ide transcriptase inhibitors and against non-nucleoside reverse-transcriptase inhibitors mutations, respectively. Two of the patients had multi-drug-resistant HIV-1. The most prevalent viral subtype was B (44, 68.8\%), followed by subtype F (11, 17.2\%). This study shows that TDR may vary according to the population studied and it may be higher in clusters of MSM.
\end{abstract}

Key words: HIV-1 - transmitted drug resistance - genotyping - recent HIV infection - men who have sex with men

Human immunodeficiency virus (HIV)-1 suppression through combined antiretroviral therapy (ART) has resulted in the reduction of acquired immune deficiency syndrome (AIDS)-related morbidity and mortality in countries where these medications are widely available (Hammer et al. 1997, Deeks 2008). However, those on non-suppressive therapy present an increased risk of developing resistance mutations due to unsuitable adherence, medication interactions and suboptimal treatment. This may limit future therapies and potentially increase the risk of transmission of resistant viral strains, with a possible impact on public health (Napravnik et al. 2005). Thus, HIV-1 resistance to ART may be a consequence of selective medication pressure and can be transmitted when a patient is either first infected or super-infected by a resistant strain. These individuals begin ART with a smaller genetic barrier and, consequently, a greater risk of virological failure and a higher potential for the development of new viral resistance mutations (Shafer et al. 2007, Gagliani et al. 2011).

The incidence and prevalence of transmitted drugresistance (TDR) are difficult to estimate and data vary widely by region, population, methods and lists of mutations used to calculate these rates. Shafer et al. (2007)

doi: $10.1590 / 0074-0276108042013012$

Financial support: DDAHV)/SVS/MS, FAPEMIG, CNPq

+ Corresponding author: unaitupi@gmail.com

Received 17 August 2012

Accepted 9 April 2013 outlined criteria for developing a list of surveillance drug resistance mutations (SDRM). These criteria were updated in 2009 (Bennett et al. 2009), making it possible to accurately compare TDR rates across geographic regions and times. In Europe and North America, TDR prevalence varies from $5-15 \%$ in chronically infected patients and from $10-25 \%$ in acute infections (Shafer et al. 2007). The prevalence in Asia is $13.8 \%$ and it ranges from 2.2-24\% in Africa (Ceccherini-Silberstein et al. 2010). Thus, TDR is a concern for the initiation of ART, mainly in developed countries, where there is wide exposure to ART (Borroto-Esoda et al. 2004, Fox et al. 2006, Turner \& Wainberg 2006). An initial study carried out by the Brazilian Ministry of Health in testing centres throughout the country found TDR in $7 \%$ of chronically infected patients, with $2.2 \%$ resistant against protease inhibitors (PIs), 2.4\% resistant against nucleos(t)ide transcriptase inhibitors (NRTIs) and 2.1\% resistant against non-nucleoside reverse-transcriptase inhibitors (NNRTIs) (Brindeiro et al. 2003). Two other important studies carried out in several Brazilian cities in 2009 found a TDR rate of $5.7 \%$ using the International AIDS Society (IAS) criteria in naïve HIV patients (Sprinz et al. 2009) and 8.1\% (Inocêncio et al. 2009) in newly infected individuals using the SDRM criteria. Due to the moderate prevalence of TDR, the Brazilian guidelines recommend genotyping prior to beginning ART only for pregnant persons and those infected by patients on treatment (MS 2008, 2013). Currently, there are no robust data justifying increasing its use (Hawkins \& Murphy 2009).

In addition to regional variation, other risk factors have been reported, such as intravenous drug use and homosexuality, and there is lower risk among hetero- 
sexuals (Little et al. 2002). Notably, the level of previous ART exposure and sample size may have an influence on TDR prevalence (Hirsch et al. 2008). A Swedish study performed between 2003-2010 showed that TDR prevalence was significantly higher among males having sex with males (MSM) $(9.5 \%)$ and clustering of TDR strains was observed in this group (Karlsson et al. 2012). A Brazilian study found a TDR prevalence of $21.4 \%$ among MSM in community-recruited samples of nine cities (Bermúdez-Aza et al. 2011).

The objective of this study was to evaluate the TDR rate among HIV+ ART-naïve patients from a cohort of MSM in Belo Horizonte, Southeast Brazil.

\section{SUBJECTS, MATERIALS AND METHODS}

Blood samples were obtained from volunteers of Horizonte Project (PBH) in Belo Horizonte, between 1996-June 2012. This project was an open cohort of HIVnegative homosexual and bisexual men supported by the Brazilian Ministry of Health and it is one of the components of the Minas Gerais HIV-AIDS Vaccine Centre of the Federal University of Minas Gerais (UFMG) in Brazil (Carneiro et al. 2000). The project objectives included the evaluation of the role of counselling and condom distribution in the incidence of HIV infection in this population. Every six months, the volunteers were examined, received counselling and preservatives and underwent serologic tests for HIV (ELISA) and other sexually transmitted diseases, such as syphilis and viral hepatitis. Five hundred and thirteen subjects are currently being followed. The eligibility criteria for enrolment included being homosexual or bisexual, 18 years or older, consenting to HIV testing and testing negative for HIV-1. All the available HIV+ samples collected after enrolment in PBH were genotyped. From the beginning of the project in 1994 until June 2012, 1,328 subjects were followed and 119 were infected with HIV-1 during this period. Genotyping was carried out on 64 samples of seroconverters between 1996-June 2012. In the remaining 55 individuals, genotyping was not possible either because the samples were not available or the pol gene was not amplified with the available kits. The elapsed time was the time between the last negative HIV-1 test and the first positive HIV-1 test. We considered an infection to be a recent HIV-1 infection when the elapsed time between the last negative HIV test and the first positive test was less than 12 months.

The ViroSeq ${ }^{\mathrm{TM}}$ Genotyping System version 2.0 (Celera Diagnostics, Alameda, California, USA) was used for genotypic analysis until 2007 and the TRUGENE ${ }^{\circledR}$ HIV-1 Genotyping Assay (Siemens Diagnostics, USA) was subsequently used.

All sequences obtained were subjected to quality control assessments using the Blast-RENAGENO Resistance Analysis Program (aids.gov.br/renageno) to exclude sample mix-up or contamination. Drug resistance was analysed using 297 nucleotides of protease (PR) (positions 1-99) and the first 1,003 nucleotides of reverse-transcriptase (RT) (positions 1-335). The amino acid sequences of the RT and PR genes were deduced from the nucleic acid sequences and compared to a subtype B consensus sequence from the Stanford HIVdb Program Genotypic Resistance Interpretation Algorithm version 6.2.0 (hivdb. stanford.edu/) RT and the PR sequence database.

In this study, the World Health Organization SDRM criteria (Bennett et al. 2009) were used to determine the significant mutations for TDR calculation. Tests for mutations associated with at least two classes of drugs were considered in multi-drug-resistant (MDR) samples.

For all the individuals included, the initial viral load (VL) and $\mathrm{CD}^{+} \mathrm{T}$ lymphocyte (CD4) counts were obtained from Control System Laboratory Tests of the National Lymphocyte Count $\mathrm{CD}^{+} / \mathrm{CD}^{+}$and Viral Load (SISCEL), a Brazilian AIDS Program Database, or from the patient files. All the seroconverters are being followed at the UFMG HIV/AIDS outpatient clinic Training and Reference Center in Infectious and Parasitic Diseases.

The data were analysed using STATA for Windows ${ }^{\circledR}$ (version 11.2, StataCorp, College Station, TX, USA). Descriptive data were presented as the mean, median and percentage. The chi-square and Mann-Whitney $U$ tests were used as appropriate. Statistical significance was set at the $5 \%$ level.

This study was conducted in accordance with the Brazilian Research Ethics Guidelines and approved by the Ethical Review Committee (UFMG).

\section{RESULTS}

Demographic and laboratory data from the 64 patients are shown in Table I. All the patients lived in Belo Horizonte or in the metropolitan region. Thirty-five patients $(54.7 \%)$ had documented recent infections $(<12$ months). The overall TDR prevalence was $14.1 \%$ (9 patients) according to the SDRM criteria (Bennett et al. 2009). Three (4.7\%), five (7.8\%) and four (6.2\%) patients presented PI, NRTI and NNRTI resistance mutations, respectively, as shown in Table II. Among the patients with TDR, four (44.4\%) had single resistance mutations and two (22.2\%) had MDR HIV-1. Resistance to three drug classes was found in one sample. Patients with and without TDR had similar CD4 cell counts (median, 531 and $476 \mathrm{cell} / \mathrm{mm}^{3}$, respectively, $\mathrm{p}=0.355$, Mann-Whitney $U$ test) and VL levels (17,746 and 14,250 copies/mL, respectively, $\mathrm{p}=0.952$, Mann-Whitney $U$ test).

Subtype B was the most prevalent $(44,68.8 \%)$, followed by F (11, 17.2\%) and C (4, 6.3\%). TDR was only found in subtype $B$, with statistically significant differences between the $\mathrm{B}$ and non-B subtypes and the presence of SDRM ( $p=0.029$, chi-square test).

\section{DISCUSSION}

This study presents data collected from MSM in Belo Horizonte, over a broad timespan (1996-2012) that encompasses different eras of HIV treatment. The TDR rate of $14.1 \%$ was moderate, but higher than in other studies in the general global population and in Brazil. Two large Brazilian TDR prevalence studies with random and representative samples were published. Brindeiro et al. (2003) found TDR in 7\% of chronically infected patients $(2.2 \%, 2.4 \%$ and $2.1 \%$ prevalence of resistance against PIs, NRTIs and NNRTIs, respectively), while Inocêncio 
et al. (2009) reported TDR in $8.1 \%$ of recently diagnosed individuals from six Brazilian capital cities among 210 samples. There were intermediate levels of TDR (5-15\%) in the cities of Belém, Brasília, São Paulo and Rio de Janeiro and the last two cities are in the Southeast Region of Brazil, which is relatively close to Belo Horizonte (Inocêncio et al. 2009). In southeastern Brazil, where the epidemic began, patients have been more exposed to ART, which is a plausible explanation for the higher rates of TDR. Our results do not differ from the overall national data (Inocêncio et al. 2009, Sprinz et al. 2009).

Studies with MSM have shown moderate rates of TDR with an apparently stable prevalence (Truong et al. 2011, Castor et al. 2012). Castor et al. (2012) showed a TDR prevalence of $14.3 \%$ in a predominantly MSM cohort with recent/acute HIV infection from 1995-2010 in New York City. A Swedish study performed in nine cities between 2003-2010 showed a 9.5\% TDR prevalence (Karlsson et al. 2012). A recent study revealed a high TDR level $(21.4 \%)$ in the city of São Paulo in community-recruited samples from MSM (Bermúdez-Aza et al. 2011).

TABLE I

Baseline characteristics of the subjects ${ }^{a}$

\begin{tabular}{lcc}
\hline & & $\begin{array}{c}\text { Transmitted drug } \\
\text { resistance } \\
\text { SDRM 2009 }\end{array}$ \\
\hline Characteristics & Patients & $9(14.1)$ \\
Total [n (\%)] & $64(100)$ & $9(14.1)$ \\
Male [n (\%)] & $64(100)$ & \\
Age (years) & & 30.1 \\
Mean & 30.6 & $22-42$ \\
Range & $19-54$ & \\
HIV subtype [n (\%)] & $44(68.8)$ & - \\
B & $11(17.2)$ & - \\
F & $4(6.3)$ & - \\
C & $5(7.8)$ & 29.4 \\
BC, BF, FB & & $6-36$ \\
Elapsed time (months) & \\
Mean & 14.5 & \\
Range & $3-74$ & 14.250 \\
Laboratory variables- & & $700-610.000$ \\
VL (copies/mL) & & \\
Median & 17.746 & $394-1.364$ \\
Range & $590-610.000$ & \\
CD4 count (cells/mL) & & \\
Median & 531 & \\
Range & $110-1.440$ & \\
\hline
\end{tabular}

$a$ : protease and reverse transcriptase subtypes/number of samples $(\mathrm{BC} / 1, \mathrm{BF} / 3$ and $\mathrm{FB} / 1)$; $b$ : from last negative human immunodeficiency virus (HIV) Elisa test and the first positive test. First positive HIV Elisa test sample was used for drugresistance testing; $c$ : for six patients there was no information on viral load (VL) and $\mathrm{CD}^{+} \mathrm{T}$ lymphocytes count; SRDM: surveillance drug resistance mutations.
According to the Brazilian genotyping interpretation system RENAGENO version 05-2012 (algoritmo.aids.gov. br) and the Stanford HIVdb Program, seven of the patients in our study would be predicted to have some degree of resistance to the initial ART regimen commonly used in Brazil (Table II), which consists of two NRTIs (AZT + $3 \mathrm{TC}$ or TDF + 3TC) and one NNRTI (EFV or NVP).

All three patients with single PI-related mutations were predicted to be fully susceptible to all the PIs. Interestingly, there were no PI-related mutations after 2005, most likely because ritonavir boosted the potency of this class. This is in agreement with TDR incidence studies that show a tendency of stabilisation or even reduction of resistance in this class (Vercauteren et al. 2008, 2009).

Our sample has limitations that may have affected the rate of TDR prevalence in this population. The major problem was the loss of 55 samples during the study; in some cases, the pol gene was not amplified with the available kits and in other cases, samples were not available after seroconversion. Another problem was that some of the patients had up to 74 months between the last HIVnegative ELISA and the first positive test and we could not determine how long they had been infected. Subsequently, more than half of the patients were found to be recently infected, that is, less than 12 months). Studies have shown that resistance mutations persist in the absence of ART, which may have been the case for those with a long elapsed time (Brenner et al. 2002, Pao et al. 2004). Other authors hypothesise that resistance may be underestimated among chronically infected individuals.

Another limitation is the relatively small sample size, which may not accurately reflect the newly HIV-infected patients in the region. However, in Belo Horizonte, the HIV epidemic is still more prevalent among MSM. We chose the SDRMs as our standard, which may have limited direct comparisons to other studies that utilised the IAS list of drug resistance mutations (IAS-DRMs). Some potentially relevant mutations are absent in the SDRM, but Green et al. (2008) showed that compared to SDRMs as the reference standard, the overall sensitivity of the IASDRMs was inferior for detecting TDR. In fact, when we applied the main IAS-DRMs in our study, there was no significant difference in the TDR rate (data not shown).

Viral subtype B was the most prevalent in this study, as has been observed in most regions of Brazil except the southern region, where subtype $\mathrm{C}$ is more common (Soares et al. 2003, Brígido et al. 2011). TDR was present only among subtype B patients, with a statistically significant difference between $\mathrm{B}$ and non-B subtypes and the presence of SDRM ( $p=0.029$, chi-square test). It is worth noting that subtype $\mathrm{C}$ was present in $6.3 \%$ $(4 / 64)$ of patients, which indicated that this subtype is spreading throughout the southeast (Soares et al. 2003, Brígido et al. 2011). There were 11 patients with subtype $\mathrm{F}$ and an increase in its prevalence has already been reported in the northeast region of Brazil; Cavalcanti et al. (2012) showed that $37.7 \%$ of patients had subtype $F$ in metropolitan city of Recife.

Furthermore, a study by Sax et al. (2005) showed that genotypic testing is cost-effective for ART-naïve patients when the TDR prevalence is $\geq 1 \%$. 


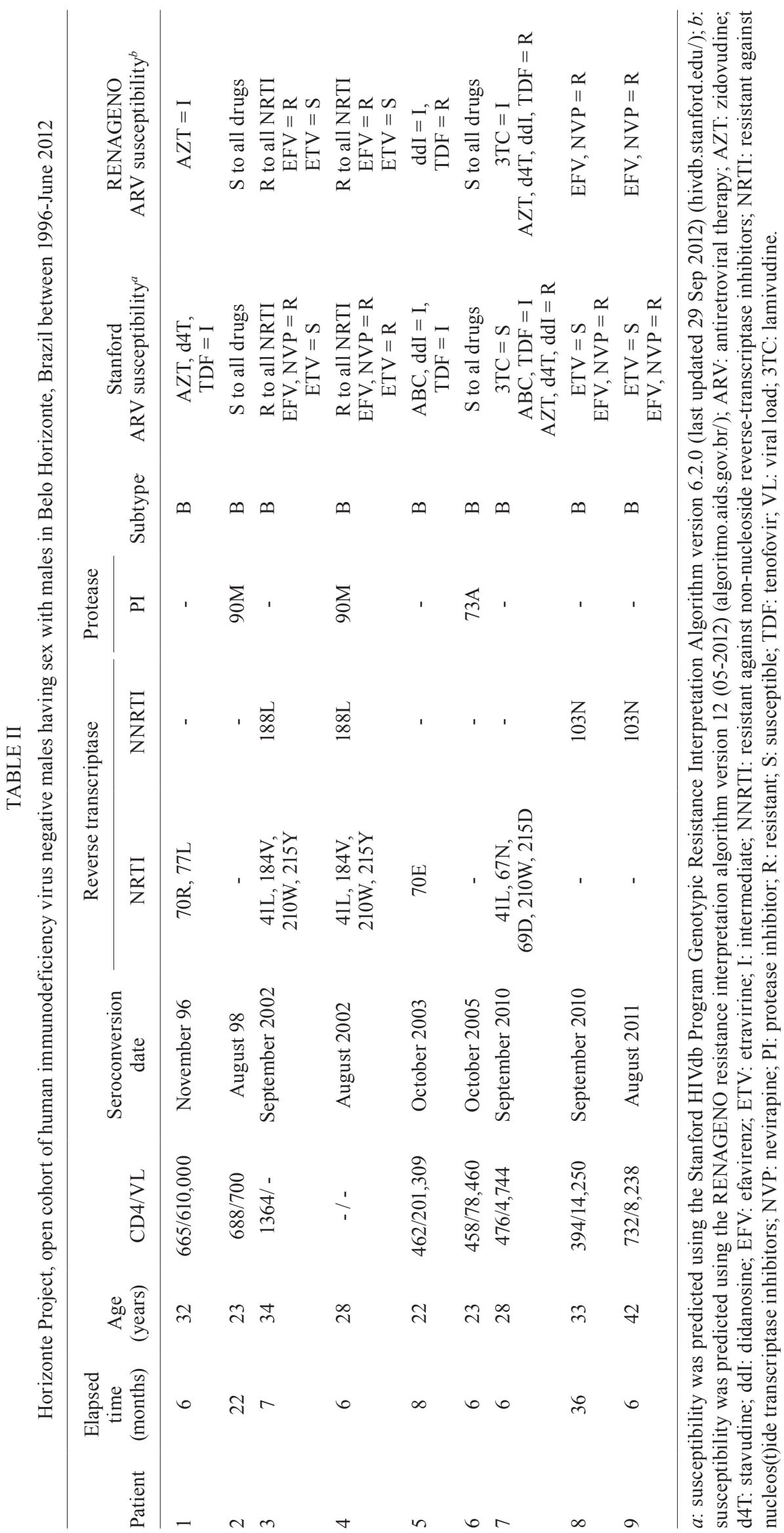


In our study, there were no statistically significant differences related to the $\mathrm{CD} 4$ count and $\mathrm{VL}$ with or without resistance mutations at the time of infection. However, we did not evaluate the clinical data from patients with SDRMs to verify how TDR may have affected the clinical outcome. The impact of TDR on surrogate markers of clinical progression (CD4 count and VL) remains uncertain. The EuroCoord-CHAIN project evaluated the effect of TDR on first-line ART. They estimated a virological failure of $4.7 \%$ at 12 months for those with TDR and fully active ART and $15.1 \%$ for those with TDR and resistance to at least one prescribed drug (Wittkop et al. 2011).

A slower rate of CD4 decline has been reported in patients who present TDR mutations (Bhaskaran et al. 2004), while others have not found a favourable effect on VL and CD4 counts in the presence of TDR mutations (Chan et al. 2003).

In conclusion, this study shows that the TDR prevalence among recently infected MSM in Belo Horizonte from 1996-2012 remained moderate and comparable with other similar studies. While the prevalence remained moderate in Belo Horizonte in this specific population, the profile of the transmitted mutations in the overall population may be different, underscoring the need for continued and improved measures for targeted interventions. Thus, TDR surveillance studies must be maintained over time, as recommended by WHO (WHO 2012), with additional national surveillance studies to identify the true rate of TDR and evaluate if genotyping tests should be performed prior to the beginning of ART in this specific population.

\section{ACKNOWLEDGEMENTS}

To the PBH team, Júlio Andrade, Silvia Cleto and all members of the Laboratory of Immunology and Molecular Biology DIP/HC/UFMG.

\section{REFERENCES}

Bennett DE, Camacho RJ, Otelea D, Kuritzkes DR, Fleury H, Kiuchi M, Heneine W, Kantor R, Jordan MR, Schapiro JM, Vandamme AM, Sandstrom P, Boucher CA, van de Vijver D, Rhee Sy, Liu TF, Pillay D, Shafer RW 2009. Drug resistance mutations for surveillance of transmitted HIV-1 drug-resistance: 2009 update. PLoS ONE 4: e4724.

Bermúdez-Aza EH, Kerr LR, Kendall C, Pinho AA, de Mello MB, Mota RS, Guimarães MD, Alencar CS, de Brito AM, Dourado IC, da Batista SM, Abreu F, de Oliveira LC, Moraes AS, Benzaken AS, Merchan-Hamann E, de Freitas GM, McFarland W, Albuquerque E, Rutherford GW, Sabino E 2011. Antiretroviral drug resistance in a respondent-driven sample of HIV-infected men who have sex with men in Brazil. $J$ Acquir Immune Defic Syndr 57 (Suppl. 3): S186-S192.

Bhaskaran K, Pillay D, Walker AS, Fisher M, Hawkins D, Gilson R, McLean K, Porter K, UK Register of HIV Seroconverters 2004. Do patients who are infected with drug-resistant HIV have a different CD4 cell decline after seroconversions? An exploratory analysis in the UK register of HIV seroconverters. AIDS 18: 1471-1473.

Borroto-Esoda K, Myrick F, Feng J, Jeffrey J, Furman P 2004. In vitro combination of amdoxovir and the inosine monophosphate dehydrogenase inhibitors mycophenolic acid and ribavirin demonstrates potent activity against wild-type and drug-resistant variants of human immunodeficiency virus type 1 . Antimicrob Agents Chemother 48: 4387-4394.
Brenner BG, Routy JP, Petrella M, Moisi D, Oliveira M, Detorio M, Spira B, Essabag V, Conway B, Lalonde R, Sekaly RP, Wainberg MA 2002. Persistence and fitness of multidrug-resistance human immunodeficiency virus type 1 acquired in primary infection. J Virol 76: 1753-1761.

Brígido LFM, Ferreira JLP, Almeida VC, Rocha SQ, Ragazzo TG, Estevam DL, Rodrigues R, the São Paulo HIV Salvage Workgroup 2011. Southern Brazil HIV type $1 \mathrm{C}$ expansion into the state of São Paulo, Brazil. AIDS Res Hum Retrov 27: 339-344.

Brindeiro RM, Diaz RS, Sabino EC, Morgado MG, Pires IL, Brígido L, Dantas MC, Barreira D, Teixeira PR, Tanuri A 2003. Brazilian network for HIV drug resistance surveillance (HIV-BResNet): a survey of chronically infected individuals. AIDS 17: 1063-1069.

Carneiro M, Antunes CMF, Greco M, Oliveira EI, Andrade JC, Lignani Jr L, Greco DB 2000. Design, implementation and evaluation at entry of a prospective cohort study of homosexual HIV-1 negative male in Belo Horizonte, Brazil (Project Horizonte). J Acquir Immune Defic Syndr 25: 182-187.

Castor D, Low A, Evering T, Karmon S, Davis B, Figueroa A, Lamar M, Garmon D, Mehandru S, Markowitz M 2012. Transmitted drug resistance and phylogenetic relationships among acute and early HIV-1 infected individuals in New York City. J Acquir Immune Defic Syndr 61: 1-8.

Cavalcanti AM, Brito AM, Salustiano DM, Lima KO, Silva SP, Diaz RS, Lacerda HR 2012. Primary resistance of HIV to antiretrovirals among individuals recently diagnosed at voluntary counselling and testing centres in the metropolitan region of Recife, Pernambuco. Mem Inst Oswaldo Cruz 107: 450-457.

Ceccherini-Silberstein F, Cento V, Calvez V, Perno C-F 2010. The use of human immunodeficiency virus resistance tests in clinical practice. Clin Microbiol Infect 16: 1511-1517.

Chan KC, Galli RA, Montaner JS, Harrigan PR 2003. Prolonged retention of drug resistance mutations and rapid disease progression in the absence of therapy after primary HIV infections. AIDS 17: $1256-1268$.

Deeks SG 2008. Transmitted minority drug-resistant HIV variants: a new epidemic? PLoS Med 5: e164.

Fox J, Dustan S, McClure M, Weber J, Fidler S 2006. Transmitted drug-resistant HIV-1 in primary HIV-1 infection; incidence, evolution and impact on response to antiretroviral therapy. HIV Med 7: 477-483.

Gagliani LH, Maia WTA, Sá-Filho D, Sucupira MC, Caseiro MM, Diaz RS 2011. The association between primary antiretroviral resistance and HAART virologic failure in a developing set. AIDS Res Hum Retrov 27: 251-256.

Green H, Tilston P, Fearnhill E, Pillay D, Dunn DT, UK Collaborative Group on HIV Drug Resistance 2008. The impact of different definitions on the estimated rate of transmitted HIV drug resistance in the United Kingdom. J Acquir Immune Defic Syndr 49: 196-204.

Hammer SM, Squires KE, Hughes MD, Grimes JM, Demeter LM, Currier JS, Eron Jr JJ, Feinberg JE, Balfour Jr HH, Deyton LR, Chodakewitz JA, Fischl MA 1997. A controlled trial of two nucleoside analogues plus indinavir in persons with human immunodeficiency virus infection and CD4 cell counts of 200 per cubic millimeter or less. AIDS Clinical Trial Group 320 Study Team. $N$ Engl J Med 337: 725-733.

Hawkins C, Murphy RL 2009. Management of antiretroviral failure and resistance in developing countries. Curr Opin HIV AIDS 4: 538-544.

Hirsch MS, Günthard HF, Schapiro JM, Brun-Vézinet F, Clotet B, Hammer SM, Johnson VA, Kuritzkes DR, Mellors JW, Pillay D, Yeni PG, Jacobsen DM, Richman DD 2008. Antiretroviral drug 
resistance testing in adult HIV-1 infection: 2008 recommendations of an international AIS Society-USA painel. Clin Infect Dis 47: $266-285$

Inocêncio LA, Pereira AA, Sucupira MCA, Fernandez JCC, Jorge CP, Souza DFC, Fink HT, Diaz RS, Becker IM, Suffert TA, Arruda MB, Macedo O, Simão M, Tanuri A 2009. Brazilian network for HIV drug resistance surveillance: a survey of individuals recently diagnosed with HIV. J Int AIDS Soc 12: 20.

Karlsson A, Björkman P, Bratt G, Ekvall H, Gisslén M, Sonnerborg A, Mild M, Albert J 2012. Low prevalence of transmitted drug resistance in patients newly diagnosed with HIV-1 infection in Sweden 2003-2010. PLoS ONE 7: e33484.

Little SJ, Holte S, Routy JP, Daar ES, Markowitz M, Collier AC, Koup RA, Mellors JW, Connick E, Conway B, Kilby M, Wang L, Whitcomb JM, Hellmann NS, Richman DD 2002. Antiretroviral-drug resistance among patients recently infected with HIV. $N$ Engl $J$ Med 347: 385-394.

MS - Ministério da Saúde do Brasil 2008. Recomendações para uso da terapia antirretroviral em adultos e adolescentes com HIV/ AIDS, 7th ed., MS, Brasília, 244 pp.

MS - Ministério da Saúde do Brasil 2013. Recomendações para uso da terapia antirretroviral em adultos e adolescentes com HIV/ AIDS no Brasil - 2013, Preliminary version, MS, Brasília, 75 pp.

Napravnik S, Edwards D, Stewart P, Stalzer B, Matteson E, Eron Jr JJ 2005. HIV-1 drug resistance evolution among patients on potent combination antiretroviral therapy with detectable viremia. $J A c$ quir Immune Defic Syndr 40: 30-40.

Pao D, Andrady U, Clarke J, Dean G, Drake S, Fisher M, Green T, Kumar S, Murphy M, Tang A, Taylor S, White D, Underhill G, Pillay D, Cane P 2004. Long term persistence of primary genotypic resistance after HIV-1 seroconversion. J Acquir Immune Defic Syndr 37: 1570-1573.

Sax PE, Islam R, Walensky RP, Losina E, Weinstein MC, Goldie SJ, Sadownik SN, Freedberg KA 2005. Should resistance testing be performed for treatment-naive HIV-infected patients? A costeffectiveness analysis. Clin Infect Dis 41: 1316-1323.

Shafer RW, Rhee SY, Pillay D, Miller V, Sandstrom P, Schapiro JM, Kuritzkes DR, Bennett D 2007. HIV-1 protease and reverse transcriptase mutations for drug resistance surveillance. AIDS 21: 215-223.
Soares MA, de Oliveira T, Brindeiro RM, Diaz RS, Sabino EC, Brigido L, Pires IL, Morgado MG, Dantas MC, Barreira D, Teixeira PR, Cassol S, Tanuri A, Brazilian network for drug resistance surveillance 2003. A specific subtype $\mathrm{C}$ of human immunodeficiency virus type 1 circulates in Brazil. AIDS 17: 11-21.

Sprinz E, Netto EM, Lima MP, Furtado JJ, Eira M, Zajdenverg R, Madruga JV, Lewi DS, Machado AA, Pedro RJ, Soares MA 2009. Primary antiretroviral drug resistance among HIV type 1-infected individuals in Brazil. AIDS Res Hum Retrov 25: 861-867.

Truong H-HM, Kellogg TA, McFarland W, Louie B, Klausner JD, Philip SS, Grant RM 2011. Sentinel surveillance of HIV-1 transmitted drug resistance, acute infection and recent infection. PLoS ONE 6: e25281.

Turner D, Wainberg MA 2006. HIV transmission and primary drug resistance. AIDS Rev 8: 17-23.

Vercauteren J, Deforche K, Theys K, Debruyne M, Duque LM, Peres S, Carvalho AP, Mansinho K, Vandamme AM, Camacho R 2008. The incidence of multidrug and full class resistance in HIV-1 infected patients is decreasing over time 2001-2006 in Portugal. Retrovirology 5: 1-8.

Vercauteren J, Wensing AM, van de Vijver DA, Albert J, Balotta C, Hamouda O, Kücherer C, Struck D, Schmit JC, Asjö B, Bruckova M, Camacho RJ, Clotet B, Coughlan S, Grossman Z, Horban A, Korn K, Kostrikis L, Nielsen C, Paraskevis D, Poljak M, Puchhammer-Stöckl E, Riva C, Ruiz L, Salminen M, Schuurman R, Sonnerborg A, Stanekova D, Stanojevic M, Vandamme AM, Boucher CA 2009. Transmission of drug-resistant HIV-1 is stabilizing in Europe. J Infect Dis 200: 1503-1508.

WHO - World Health Organization 2012. World Health Organization global strategy for the surveillance and monitoring of HIV drug resistance: an update. Available from: apps.who.int/iris/bitstream /10665/77349/1/9789241504768_eng.pdf.

Wittkop L, Günthard HF, de Wolf F, Dunn D, Cozzi-Lepri A, de Luca A, Kücherer C, Obel N, von Wyl V, Masquelier B, Stephan C, Torti C, Antinori A, García F, Judd A, Porter K, Thiébaut R, Castro H, van Sighem Al, Colin C, Kjaer J, Lundgren JD, Paredes R, Pozniak A, Clotet B, Philips A, Pillay D, Chêne G, EurocoordCHAIN Study Group 2011. Effect of transmitted drug resistance on virological and immunological response to initial combination antiretroviral therapy for HIV (Euro Coord-CHAIN joint project): a European multicohort study. Lancet Infect Dis 11: 363-371. 